\title{
Serum magnesium and visfatin levels in newly diagnosed non-obese type 2 diabetes without insulin resistance: a cross-sectional study
}

\section{ABSTRACT}

Background. Previous studies demonstrated that type 2 diabetes (T2D) patients have low serum magnesium and high serum levels of visfatin. This study aimed to show the relationship between serum levels of insulin, visfatin, and magnesium in T2D patients characterized by a non-insulin resistance status.

Methods. This was a cross-sectional study conducted in the Hawler Medical University, Kurdistan Region, Iraq from April 2019 to March 2020. A total number of 130 T2D patients and 45 healthy subjects were enrolled in the study. T2D patients with scores of homeostasis model assessment - insulin resistance (HOMA-IR) of $<2.5$ were included. Serum levels of magnesium, visfatin, and glycemic indices, including fasting serum glucose, insulin, visfatin, and glycated hemoglobin were determined.

Results. The serum level of visfatin is significantly higher in T2D patients than the corresponding values of the healthy subjects. Serum magnesium level is significantly correlated with the percentage of the glycated hemoglobin (Spearman's correlation factor $=0.184$,

Address for correspondence:

Marwan SM Al-Nimer

Department of Pharmacology and Toxicology

College of Pharmacy

Hawler Medical University

Kurdistan region, Erbil, Iraq

Phone: +964 07902600291

e-mail: alnimermarwan@ymail.com

Clinical Diabetology 2020, 10, 1: 123-128

DOI: $10.5603 /$ DK.2020.0063

Received: 03.07.2020

Accepted: 03.11.2020
$P=0.036)$, and a positive significant correlation between serum insulin and visfatin $(r=0.216, P=0.014)$ was observed. Multivariate regression analysis of the association of fasting serum insulin as a dependent variable with serum magnesium and visfatin as independent variables showed a non-significant positive correlation ( $r=0.197, P=0.082$ ).

Conclusion. Significant low serum levels of magnesium and visfatin are observed in non-insulin resistant T2D patients with a HOMA-IR score of $<2.5$. Serum visfatin and magnesium levels showed significant correlations with glycemic indices. (Clin Diabetol 2020; 10, 1: 123-128)

Key words: magnesium, visfatin, glycemic indices, homeostasis model assessment insulin resistance, relationship

\section{Introduction}

Several substances have a hypoglycemic effect in T2D through their actions as cofactors in releasing insulin or increasing the transporting of glucose into the cell. The sources of these substances are either endogenous (i.e. they naturally occur inside the body) or exogenous (i.e. nutritional supplement). Magnesium is an example of an exogenous hypoglycemic cation, while visfatin is an example of endogenous hypoglycemic adipocytokine [1, 2].

Magnesium is an intracellular cation that exerts multiple functions in the body besides its nutritional effect. It acts as a cofactor in the metabolism of carbohydrates through its effects on the transporting of glucose and releasing of insulin [3, 4]. Low serum magnesium level in T2D diabetes is a common laboratory 


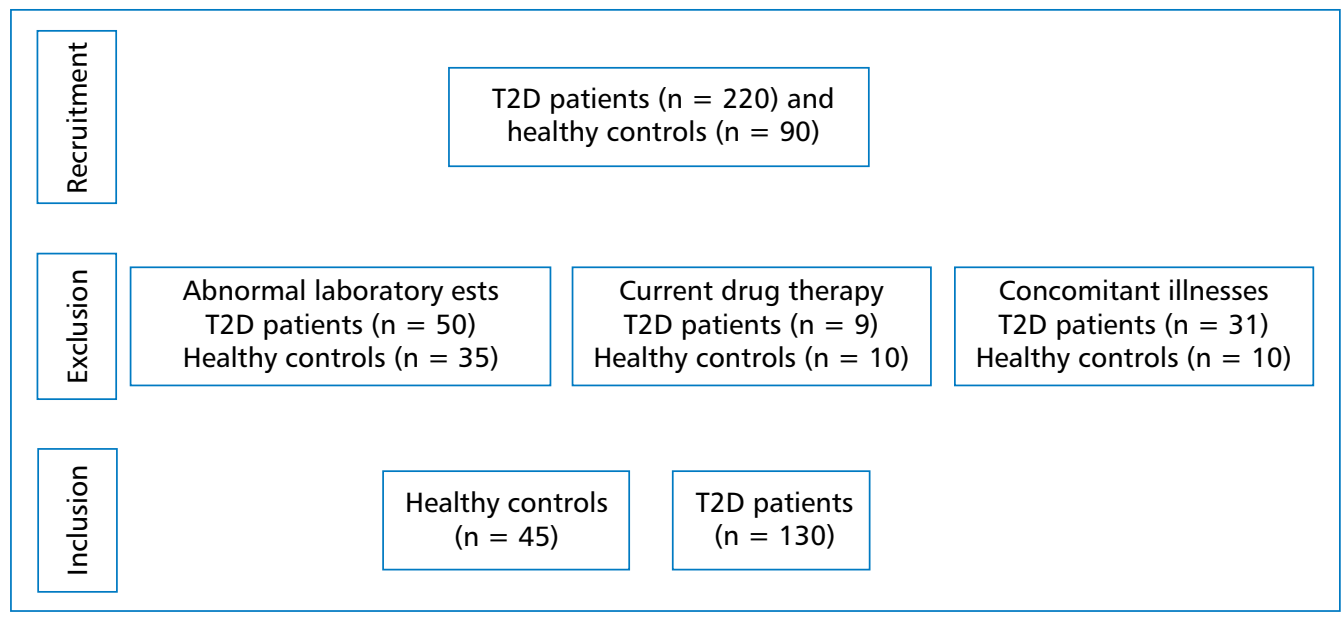

Figure 1. Recruitment, inclusion and exclusion of participants

investigation, which is associated with complications including macroangiopathy, neuropathy retinopathy, and nephropathy $[5,6]$. In diabetes mellitus, magnesium supplementation reduces fasting plasma glucose levels by $4.64 \mathrm{mg} / \mathrm{dL}$ [7]. The hypoglycemic effect of magnesium significantly reduces the score of HOMA-IR by 0.57 [8]. Visfatin (nicotinamide phosphoribosyltransferase) is an adipocytokine synthesized and released by fat cell. It has a hypoglycemic effect by binding the insulinreceptor and increasing the serum free insulin level [9] Serum level of visfatin is higher in T2D compared with healthy subjects, which is related to the fasting status of diabetic patients [10]. High serum visfatin levels were observed in T2D patients with insulin resistance, obesity, and laboratory evidence of inflammation [11]. Previous studies assessed the serum level of visfatin and magnesium in T2D patients with insulin resistance and diabetic complications. The rationale of this study is both magnesium and visfatin can regulate the fasting serum glucose in T2D patient without evidence of insulin resistance or diabetic complications. Therefore, this study aimed to show the link between the triad of fasting serum insulin, magnesium, and visfatin in patients without laboratory evidence of insulin resistance with a HOMA-IR of less than 2.5.

\section{Methods}

Ethics statement

The institutional ethics and scientific committees of Hawler Medical University approved this cross-sectional study (Project No. HMU-PH-EC 191105/98).

\section{Participants}

Two hundred twenty patients with newly diagnosed T2D and 90 healthy controls (sex- and age- matched) were recruited from Diabetic Centre in ErbilIraq during the period from April 2019 to March 2020 in the present study (Fig. 1). The study was conducted in Erbil and therefore it included a sample of Kurdish population.

\section{Criteria of inclusion}

Newly diagnosed T2D patients aged 35-79 years were included. T2D was defined by the criteria of the American Diabetes Association (fasting blood glucose level $\geq 126 \mathrm{mg} / \mathrm{dL}$ and/or 2-h postprandial blood glucose level $\geq 200 \mathrm{mg} / \mathrm{dL}$ ) [12].

\section{Criteria of exclusion}

Participants treated with insulin or oral antidiabetic agents, non-steroidal anti-inflammatory drugs, and nutritional supplements were excluded. Participants with endocrinal or bone disorders; renal and liver diseases; pregnancy and breastfeeding women were excluded. Participants with abnormal laboratory investigations, including liver and renal function tests, lipid profile, and positive results of inflammatory markers, were excluded (Figure 1). The body weight $(\mathrm{kg})$ and the height $(\mathrm{m})$ were measured for calculation the body mass index $\left(\mathrm{kg} / \mathrm{m}^{2}\right)$, and any participant with a body mass index $\geq 30 \mathrm{~kg} / \mathrm{m}^{2}$ was excluded. A total number of $130 \mathrm{~T} 2 \mathrm{D}$ patients and 45 healthy subjects were included in the laboratory determination of serum insulin, visfatin, and magnesium levels.

\section{Laboratory measurements}

A 12-h overnight fasting venous blood samples were drawn from all participants, and divided into two portions. The first portion was drawn into an EDTA-test tube for determination of the $\mathrm{HbA}_{1 \mathrm{c}}$ (Roche/Germany 
Table 1. Characteristics of the participants

\begin{tabular}{|c|c|c|c|}
\hline Determinant & Healthy subjects $(n=45)$ & Type 2 diabetes patients $(n=130)$ & P value \\
\hline Sex (Male : Female) & $18: 27$ & $48: 82$ & 0.714 \\
\hline Age (years) & $51.4 \pm 9.1$ & $51.7 \pm 10.5$ & 0.171 \\
\hline Body weight $[\mathrm{kg}]$ & $76.0 \pm 11.3$ & $76.8 \pm 10.9$ & 0.674 \\
\hline Height $[\mathrm{m}]$ & $1.67 \pm 0.15$ & $1.66 \pm 0.10$ & 0.615 \\
\hline Body mass index $\left[\mathrm{kg} / \mathrm{m}^{2}\right]$ & $27.3 \pm 2.3$ & $27.7 \pm 1.3$ & 0.157 \\
\hline Fasting serum glucose $[\mathrm{mmol} / \mathrm{L}]$ & $6.07 \pm 0.11$ & $9.84 \pm 1.23$ & $<0.001$ \\
\hline Glycated hemoglobin (\%) & $5.44 \pm 0.07$ & $8.90 \pm 0.8$ & $<0.001$ \\
\hline HOMA-IR & $0.65 \pm 0.19$ & $1.71 \pm 0.22$ & $<0.001$ \\
\hline Quicki & $0.417 \pm 0.023$ & $0.353 \pm 0.007$ & 0.002 \\
\hline HOMA- $\beta$ cell (\%) & $18.78 \pm 5.19$ & $12.84 \pm 2.77$ & $<0.001$ \\
\hline HOMA-IS (\%) & $1.673 \pm 0.54$ & $0.596 \pm 0.081$ & $<0.001$ \\
\hline Serum magnesium [mg/dL] & $1.661 \pm 0.341$ & $0.979 \pm 0.106$ & $<0.001$ \\
\hline Serum visfatin $[\mathrm{ng} / \mathrm{mL}]$ & $30.9 \pm 4.0$ & $42.9 \pm 2.6$ & $<0.001$ \\
\hline
\end{tabular}

$P$ value was calculated using independent two-sample t-test and Chi-square test. HOMA — homeostatic model assessment; IR — insulin resistance; IS - insulin sensitivity; Quicki - quantitative insulin sensitivity check index

Kit). The second portion was drawn into a non-coagulant test tube, left for $30 \mathrm{~min}$ for coagulation, and then centrifuged for $15 \mathrm{~min}$ at 3,000 r.p.m. The sera of the patients were separated for determination of serum magnesium, glucose, insulin, and visfatin. Serum glucose, insulin, and magnesium were determined using automated analyzer for clinical chemistry analysis (Cobas, Roche, and Hitachi, Germany). Visfatin (Elabscience, USA kit) was determined using enzyme-linked immunosorbent assay (ELISA) technology.

\section{Calculation of insulin resistance} and sensitivity scores

\section{Homeostasis model assessment-insulin resistance (HOMA-IR)}

HOMA-IR = fasting serum glucose $[\mathrm{mmol} / \mathrm{L}] \times$ fasting serum insulin $[\mu \mathrm{U} / \mathrm{mL}] / 22.5$

Previous studies used different cut-off values of HOMA-IR for insulin resistance. In our population, a cut-off value of $\geq 2.5$ was used as indicator of insulin resistance based on the clinical studies and was used by others [13].

\section{Assessment of $\beta$-cell function}

HOMA- $\beta=(20 \times$ fasting serum insulin $[\mu \mathrm{U} / \mathrm{mL}]) /$ /(fasting serum glucose -3.5$)$. The result is expressed as a percentage.

\section{Homeostasis model assessment-insulin sensitivity (HOMA-IS)}

The value of HOMA-IS is calculated by inverting the HOMA-IR.

HOMA-IS = 1/HOMA-IR

\section{Quantitative insulin sensitivity check index (Quicki)}

This index is simply calculated using the following equation:

$$
\begin{aligned}
\text { QUICKI } & =1 /[\log (\text { fasting serum insulin }(\mu \mathrm{U} / \mathrm{mL})+ \\
+ & \log (\text { fasting serum glucose }(\mathrm{mg} / \mathrm{dL})]
\end{aligned}
$$

\section{Statistical analysis}

Data were analyzed using SPSS version 20. Student's $t$ test was used to compare differences between independent two samples and one-way analysis of variance (ANOVA) to compare differences between age groups and sex categories. Chi-squared test was used to compare the distribution of sex between healthy subjects and T2D patients. Spearman's correlation ( $r$ ) and multivariate regression analysis were calculated to show the inter-relationship between the fasting insulin level as a dependent variable and serum magnesium and visfatin as independent variables. P value of $<0.05$ indicated statistical significance.

\section{Results}

Table 1 shows the characteristics of the participants enrolled in the study. There are no significant differences between healthy subjects and T2D patients in the mean \pm SD of age and distribution of participants according to the sex. Significant differences in the glycemic indices between healthy subjects and T2D patients were observed, and these changes were associated with significantly higher serum level of visfatin and lower serum level of magnesium in T2D patients compared with healthy subjects. 
Table 2. The mean \pm SD of glycemic indices, serum levels of visfatin and magnesium according to the sex distribution

\begin{tabular}{lcccc}
\hline Variables & Female $(\mathbf{n}=\mathbf{8 2})$ & Male $(\mathbf{n}=\mathbf{4 8})$ & Total $(\mathbf{n}=\mathbf{1 3 0})$ & P value \\
\hline Age (years) & $51.2 \pm 10.5$ & $52.7 \pm 10.5$ & $51.7 \pm 10.5$ & 0.448 \\
Serum glucose $[\mathrm{mmol}]$ & $9.85 \pm 1.19$ & $9.81 \pm 1.3$ & $9.84 \pm 1.23$ & 0.871 \\
Glycated hemoglobin $(\%)$ & $8.98 \pm 0.79$ & $8.76 \pm 0.80$ & $8.90 \pm 0.8$ & 0.124 \\
Serum insulin $[\mu \mathrm{U}]$ & $3.91 \pm 0.08$ & $3.90 \pm 0.08$ & $3.91 \pm 0.08$ & 0.685 \\
HOMA-IR & $1.71 \pm 0.21$ & $1.70 \pm 0.23$ & $1.71 \pm 0.22$ & 0.833 \\
Quicki & $0.352 \pm 0.007$ & $0.353 \pm 0.008$ & $0.353 \pm 0.007$ & 0.763 \\
HOMA- $\beta$ cell (\%) & $12.77 \pm 2.64$ & $12.94 \pm 3.01$ & $12.84 \pm 2.77$ & 0.736 \\
HOMA-IS (\%) & $0.594 \pm 0.078$ & $0.599 \pm 0.088$ & $0.596 \pm 0.081$ & 0.727 \\
Serum magnesium $[\mathrm{mg} / \mathrm{dL}]$ & $0.990 \pm 0.106$ & $0.959 \pm 0.103$ & $0.979 \pm 0.106$ & 0.105 \\
Serum visfatin $[\mathrm{ng} / \mathrm{mL}]$ & $43.0 \pm 2.7$ & $42.6 \pm 2.39$ & $42.9 \pm 2.6$ & 0.440 \\
\hline
\end{tabular}

P value was calculated using independent two-sample t-test and Chi-square test. HOMA — homeostatic model assessment; IR — insulin resistance; IS - insulin sensitivity; Quicki — quantitative insulin sensitivity check Index

There is no significant difference between males and females in the serum levels of glycemic indices, visfatin, and magnesium (Table 2). The mean values of HOMA-IR and Quicki are 1.71 and 0.353 , indicating the patients in the state of non-insulin resistance. The percentage of the $\beta$-cell function is 12.84 . Figure 2 shows that the mean serum level of visfatin is significantly higher in T2D patients than the corresponding value of the healthy subjects. Table 3 shows that there are nonsignificant differences in the glycemic indices, serum visfatin, and magnesium level between age groups of patients. Serum magnesium level is significantly correlated with the percentage of the glycated hemoglobin (Spearman correlation factor $=0.184, P=0.036$ ), while there was a positive nonsignificant correlation of glycated hemoglobin (\%) with insulin ( $r=0.136, P=0.123)$ and visfatin $(r=0.001, P=0.993)$. Serum insulin significantly positively correlated with visfatin $(r=0.216, P=0.014)$,

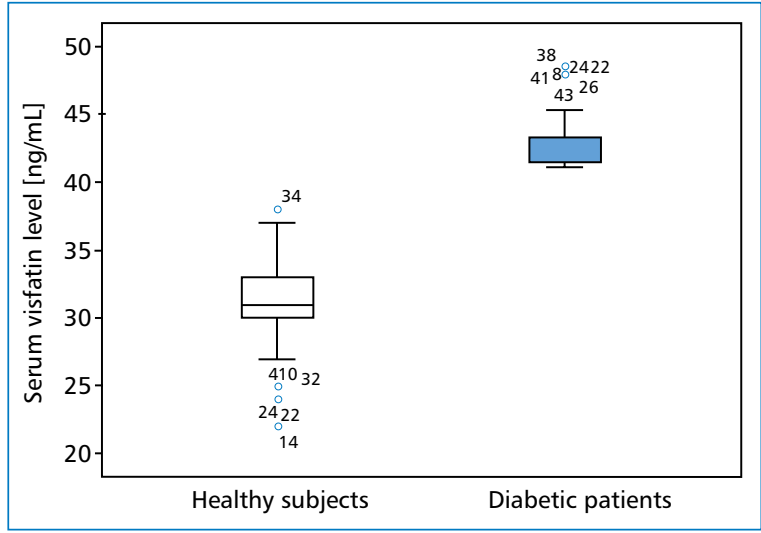

Figure 2. Boxplot of serum level of visfatin in T2D patients compared with the healthy subjects

but there are no significant correlations of serum magnesium with insulin or visfatin. Multivariate regression analysis of the association of fasting serum insulin as

Table 3. The mean \pm SD of glycemic indices, serum levels of visfatin and magnesium according to age groups

\begin{tabular}{|c|c|c|c|c|c|c|c|}
\hline \multirow[t]{2}{*}{ Variables } & \multicolumn{7}{|c|}{ Age group (years) } \\
\hline & $\begin{array}{c}31-40 \\
(n=20)\end{array}$ & $\begin{array}{c}41-50 \\
(n=43)\end{array}$ & $\begin{array}{c}51-60 \\
(n=39)\end{array}$ & $\begin{array}{c}61-70 \\
(n=19)\end{array}$ & $\begin{array}{l}71-80 \\
(n=9)\end{array}$ & F value & $P$ value \\
\hline Age (years) & $38.1 \pm 2.0$ & $45.3 \pm 2.6$ & $54.2 \pm 2.8$ & $65.2 \pm 2.8$ & $73.4 \pm 2.8$ & & \\
\hline Serum glucose [mmol] & $9.32 \pm 1.23$ & $9.91 \pm 1.17$ & $10.0 \pm 1.23$ & $9.97 \pm 1.15$ & $9.66 \pm 1.59$ & 1.190 & 0.319 \\
\hline Glycated hemoglobin (\%) & $8.97 \pm 0.64$ & $8.97 \pm 0.79$ & $8.99 \pm 0.80$ & $8.45 \pm 0.87$ & $8.94 \pm 0.88$ & 1.791 & 0.135 \\
\hline Serum insulin $[\mu \mathrm{U}]$ & $3.91 \pm 0.07$ & $3.91 \pm 0.08$ & $3.91 \pm 0.07$ & $3.90 \pm 0.08$ & $3.87 \pm 0.08$ & 0.784 & 0.538 \\
\hline HOMA-IR & $1.62 \pm 0.22$ & $1.72 \pm 0.21$ & $1.74 \pm 0.22$ & $1.73 \pm 0.21$ & $1.66 \pm 0.27$ & 1.154 & 0.334 \\
\hline Quicki & $0.356 \pm 0.008$ & $0.352 \pm 0.007$ & $0.352 \pm 0.007$ & $0.352 \pm 0.007$ & $0.355 \pm 0.009$ & 1.223 & 0.305 \\
\hline HOMA- $\beta$ (\%) & $14.1 \pm 3.2$ & $12.62 \pm 2.51$ & $12.51 \pm 2.67$ & $12.44 \pm 2.38$ & $13.43 \pm 3.92$ & 1.380 & 0.245 \\
\hline HOMA-S (\%) & $0.628 \pm 0.091$ & $590 \pm 0.075$ & $0.584 \pm 0.079$ & $0.587 \pm 0.072$ & $0.618 \pm 0.108$ & 1.251 & 0.293 \\
\hline Magnesium [mg/dL] & $0.973 \pm 0.095$ & $0.982 \pm 0.093$ & $0.984 \pm 0.113$ & $0.976 \pm 0.117$ & $0.957 \pm 0.144$ & 0.151 & 0.962 \\
\hline Visfatin [ng/mL] & $42.6 \pm 2.3$ & $42.9 \pm 2.6$ & $43.2 \pm 2.8$ & $42.1 \pm 2.1$ & $43.2 \pm 2.9$ & 0.640 & 0.635 \\
\hline
\end{tabular}

P value was calculated using independent two-sample t-test and Chi-square test. HOMA — homeostatic model assessment; IR — insulin resistance; IS - insulin sensitivity; Quicki - quantitative insulin sensitivity check Index 


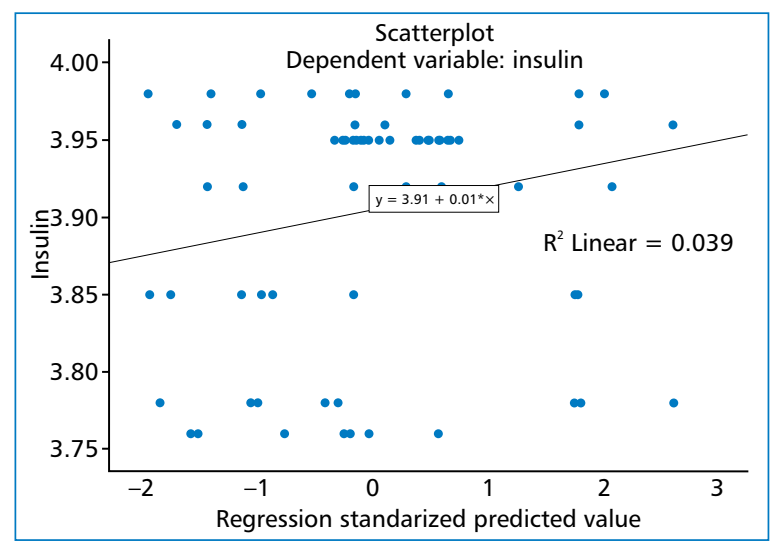

Figure 3. Multivariate regression analysis of the association between fasting serum insulin level as dependent variable and serum magnesium and visfatin a s independent variables

a dependent variable with serum magnesium and visfatin as independent variables showed a nonsignificant positive correlation $(r=0.197, F=2.522, P=0.082$, $\left.\mathrm{df}=129, \mathrm{R}^{2}=0.039\right)$ that applied to $3.9 \%$ of patients (Fig. 3). The expected insulin value $=3.702+$ (serum magnesium $\times 0.133)$, t-value $2.128, \mathrm{P}=0.035$, while the expected insulin value $=3.702+$ (serum visfatin $\times 0.002$ ), t-value $0.674, \mathrm{P}=0.502$.

\section{Discussion}

The results of this study showed that diabetic patients have a significantly lower mean value of visfatin than the corresponding mean level of healthy subjects, which does not show a significant difference between sexes and age groups. Serum visfatin significantly correlated with the fasting serum insulin, but it did not correlate with serum magnesium level. A high serum visfatin level in T2D patients with a mean value of HOMA-IR less than 2.5 indicates that visfatin is a marker of insulin sensitivity. Previous studies showed that there is no relationship between serum visfatin level and HOMA-IR, and visfatin is not a cause of insulin resistance $[14,15]$. A positive significant correlation of serum visfatin levels with fasting serum insulin levels indicates that there is a relationship between visfatin and insulin to reduce the serum level of glucose. Previous studies demonstrated that hyperglycemia induced by exogenous glucose in healthy subjects elevated the serum levels of visfatin, while hyperinsulinemia suppressed the release of visfatin [16]. Further study demonstrated the inhibitory effect of insulin on the release of visfatin from adipocyte in in vitro study [17]. It is important to mention that serum visfatin level does not show relation to sex, age, body weight, and lipid profile status [17]. The serum level of magnesium is below the normal cut-off level (1.7-2.2 $\mathrm{mg} / \mathrm{dL}$ ) in T2D patients, which is due to deficiency of insulin. From the physiological point of view, insulin enhances the magnesium uptake by insulin-sensitive tissue, and there is an inverse relationship between serum magnesium and insulin levels [4]. Hypomagnesemia is frequently observed in one-third of T2D patients, which is not related to the age or sex but related to the duration of diabetes and sometimes associated with diabetic complications $[5,18]$. The results of this study showed a low serum level of magnesium in insulin-sensitive T2D patients. Moreover, magnesium supplementation for months can improve the serum glucose level, glycated hemoglobin, and HOMA-IR in T2D patients [19]. There is no relationship between serum visfatin with magnesium levels in non-diabetic patients [20]. The results of this study showed that the serum level of insulin could be evaluated from the serum level of magnesium but not the level of visfatin. This observation agreed with previous studies that reported a decrease of $0.1 \mathrm{mmol} / \mathrm{L}$ in serum magnesium level carried a risk of development of diabetes with a hazard ratio of 1.8 [21].

This study highlights important findings that determination of serum visfatin serves as an indicator of insulin sensitivity status, while determination of serum magnesium can be used to assess the serum insulin level in T2D patients with HOMA-IR index below the threshold of 2.5. Moreover, this is the first study carried on a sample of Kurdish population in Erbil.

\section{Limitations of the study}

Limitations of the study are the data of T2D patients with HOMA-IR > 2.5 are not included and we did not measure the serum levels of adipocytokines.

\section{Conclusions}

We conclude that T2D patients with HOMA-IR less than 2.5 have abnormal values of serum magnesium and visfatin, which indicates that the changes in these biomarkers are independent to the insulin resistance.

\section{Acknowledgement}

The authors thank the patients for their cooperation and the medical staffs in the laboratories of the Rizgary Teaching Hospital for doing the laboratory tests.

\section{Conflict of interest}

The authors declare that there are no conflicts of interest.

\section{REFERENCES}

1. Gommers LMM, Hoenderop JGJ, Bindels RJM, et al. Hypomagnesemia in Type 2 Diabetes: A Vicious Circle? Diabetes. 2016; 65(1): 3-13, doi: 10.2337/db15-1028, indexed in Pubmed: 26696633. 
2. Kumari B, Yadav UCS. Adipokine visfatin's role in pathogenesis of diabesity and related metabolic derangements. Curr Mol Med. 2018; 18(2): 116-125, doi: 10.2174/1566524018666180705114 131, indexed in Pubmed: 29974830.

3. Mooren FC. Magnesium and disturbances in carbohydrate metabolism. Diabetes Obes Metab. 2015; 17(9): 813-823, doi: 10.1111/dom.12492, indexed in Pubmed: 25974209.

4. Takaya J, Yamato F, Kaneko K, et al. Intracellular magnesium and insulin resistance. Magnes Res. 2004; 17(2): 126-136, indexed in Pubmed: 15319146.

5. Zhang Y, Li Q, Xin Yi, et al. Association between serum magnesium and common complications of diabetes mellitus. Technol Health Care. 2018; 26(S1): 379-387, doi: 10.3233/THC-174702, indexed in Pubmed: 29758962.

6. Zhang Qi, Ji L, Zheng $\mathrm{H}$, et al. Low serum phosphate and magnesium levels are associated with peripheral neuropathy in patients with type 2 diabetes mellitus. Diabetes Res Clin Pract. 2018; 146: 1-7, doi: 10.1016/j.diabres.2018.09.015, indexed in Pubmed: 30273706 .

7. Verma H, Garg R. Effect of magnesium supplementation on type 2 diabetes associated cardiovascular risk factors: a systematic review and meta-analysis. J Hum Nutr Diet. 2017; 30(5): 621-633, doi: 10.1111/jhn.12454, indexed in Pubmed: 28150351.

8. Veronese N, Watutantrige-Fernando S, Luchini C, et al. Effect of magnesium supplementation on glucose metabolism in people with or at risk of diabetes: a systematic review and meta-analysis of double-blind randomized controlled trials. Eur J Clin Nutr. 2016; 70(12): 1354-1359, doi: 10.1038/ejen.2016.154, indexed in Pubmed: 27530471.

9. Radzicka S, Pietryga $M$, Iciek $R$, et al. The role of visfatin in pathogenesis of gestational diabetes (GDM). Ginekol Pol. 2018; 89(9): 518-521, doi: 10.5603/GP.a2018.0088, indexed in Pubmed: 30318580.

10. Legakis I, Mantzouridis T, Bouboulis G, et al. Reciprocal changes of serum adispin and visfatin levels in patients with type 2 diabetes after an overnight fast. Arch Endocrinol Metab. 2016; 60(1): 76-78, doi: 10.1590/2359-3997000000147, indexed in Pubmed: 26909486

11. Hetta HF, Ez-Eldeen ME, Mohamed GA, et al. Visfatin serum levels in obese type 2 diabetic patients: relation to proinflammatory cytokines and insulin resistance. Egypt J Immunol. 2018; 25(2): 141-151, indexed in Pubmed: 30600957.
12. American Diabetes Association. 2. Classification and Diagnosis of Diabetes: . Diabetes Care. 2019; 42(Suppl 1): S13-S28, doi: 10.2337/dc19-S002, indexed in Pubmed: 30559228.

13. Singh $\mathrm{Y}$, Garg MK, Tandon N, et al. A study of insulin resistance by HOMA-IR and its cut-off value to identify metabolic syndrome in urban Indian adolescents. J Clin Res Pediatr Endocrinol. 2013; 5(4): 245-251, doi: 10.4274/Jcrpe.1127, indexed in Pubmed: 24379034.

14. Mihai G, Gasparik Al, Pascanu IM, et al. The influence of Visfatin, RBP-4 and insulin resistance on bone mineral density in women with treated primary osteoporosis. Aging Clin Exp Res. 2019; 31(6): 889-895, doi: 10.1007/s40520-019-01206-6, indexed in Pubmed: 31054116.

15. Heo YuJ, Choi SE, Jeon JaY, et al. Visfatin induces inflammation and insulin resistance via the NF-B and STAT3 signaling pathways in hepatocytes. J Diabetes Res. 2019; 2019: 4021623, doi: 10.1155/2019/4021623, indexed in Pubmed: 31396538.

16. Haider DG, Schaller G, Kapiotis S, et al. The release of the adipocytokine visfatin is regulated by glucose and insulin. Diabetologia. 2006; 49(8): 1909-1914, doi: 10.1007/s00125-006-0303-7, indexed in Pubmed: 16736128

17. Bala M, Martin J, Kopp A, et al. In vivo suppression of visfatin by oral glucose uptake: evidence for a novel incretin-like effect by glucagon-like peptide-1 (GLP-1). J Clin Endocrinol Metab. 2011; 96(8): 2493-2501, doi: 10.1210/jc.2011-0342, indexed in Pubmed: 21677044.

18. Noor MM, Nazir Q, Khan TM, et al. Association between low serum magnesium level and type 2 diabetes mellitus in abbottabad. J Ayub Med Coll Abbottabad. 2019; 31(2): 226-229, indexed in Pubmed: 31094121.

19. Simental-Mendía LE, Sahebkar A, Rodríguez-Morán M, et al. A systematic review and meta-analysis of randomized controlled trials on the effects of magnesium supplementation on insulin sensitivity and glucose control. Pharmacol Res. 2016; 111: 272-282, doi: 10.1016/j.phrs.2016.06.019, indexed in Pubmed: 27329332.

20. Soyoral YU, Erkoc R, Begenik H, et al. Relationship between visfatin and some clinical and biochemical parametres in peritoneal dialysis patients. J Pak Med Assoc. 2012; 62(11): 1179-1183, indexed in Pubmed: 23866406.

21. Kieboom BCT, Ligthart S, Dehghan A, et al. Serum magnesium and the risk of prediabetes: a population-based cohort study. Diabetologia. 2017; 60(5): 843-853, doi: 10.1007/s00125-0174224-4, indexed in Pubmed: 28224192. 